\title{
Analisis Faktor-Faktor yang Memengaruhi Nasabah Non-Muslim dalam Menggunakan Jasa Bank Syariah di DKI Jakarta
}

\author{
Fithri Tyas Hapsari \& Irfan Syauqi Beik \\ Program Studi Ilmu Ekonomi Syariah, Fakultas Ekonomi dan Manajemen, Institut Pertanian \\ Bogor
}

\begin{abstract}
Islamic banking industry in Indonesia experienced significant growth and development, despite its market share is still small, i.e around 4.9\%. Islamic bank is an intermediary institution based on sharia, which serve both muslim and non-muslim. This study analyzes the factors that affect non-Muslim customers in using the services of Islamic banks in Jakarta. Respondents used in this study consist of 50 non-Muslim customers of Islamic banks and 50 non-Muslim customers of conventional banks. The method used is the logistic regression method. Descriptive analysis methods is used to see the trend of non-Muslim customers towards Islamic banks. Factors that are significantly affecting non-Muslim customers in using the services of Islamic banks in Jakarta are the location factor with an odds ratio value of 1.450 , factor of administrative advantages with an odds ratio value of 6.790 , and religious stimulant factor with an odds ratio value of 2.679 .
\end{abstract}

Keywords: Islamic Bank, Non-Muslims, Logistic Regression

\begin{abstract}
Abstrak. Industri perbankan syariah di Indonesia mengalami pertumbuhan dan perkembangan yang signifikan meskipun pangsa pasarnya masih kecil, yaitu sekitar 4,9\%. Bank syariah adalah sebuah lembaga intermediasi berdasarkan prisip syariah yang melayani baik muslim dan nonmuslim. Studi ini menganalisis faktor-faktor yang mempengaruhi pelanggan non-Muslim dalam menggunakan jasa bank syariah di Jakarta. Responden yang digunakan dalam penelitian ini terdiri dari 50 pelanggan non-Muslim dari bank syariah dan 50 pelanggan non-Muslim dari bank konvensional. Metode yang digunakan adalah metode regresi logistik. Metode analisis deskriptif digunakan untuk melihat tren pelanggan non-Muslim terhadap bank syariah. Faktor-faktor yang secara signifikan mempengaruhi pelanggan non-Muslim dalam menggunakan jasa bank syariah di Jakarta adalah faktor lokasi dengan nilai odds ratio dari 1.450, faktor keuntungan administrasi dengan nilai rasio odds 6,790, dan faktor stimulan agama dengan rasio odds nilai 2,679.
\end{abstract}

Kata kunci: Bank Syariah, Non-Muslim, regresi logistik

\section{PENDAHULUAN}

\section{Latar Belakang}

Sistem perbankan yang dimiliki Indonesia adalah dual banking system atau sistem perbankan ganda. Sistem perbankan syariah dan sistem perbankan konvensional bersama- 
sama berjalan sebagai lembaga intermediasi. Selain berdirinya Bank Umum Syariah (BUS), bank konvensional juga dapat membuka Unit Usaha Syariah (UUS).

Statistik perbankan syariah yang diperoleh dari Bank Indonesia (BI) menunjukkan jumlah aset BUS dan UUS selalu mengalami kenaikan dari tahun ke tahun. Kenaikan terjadi pada jumlah aset, Dana Pihak Ketiga (DPK), dan juga Pembiayaan Yang Diberikan (PYD).

Tabel 1 Aset Bank Umum Syariah dan Unit Usaha Syariah

\begin{tabular}{rrrr}
\hline Tahun & $\begin{array}{c}\text { Jumlah Aset } \\
\text { (Miliar Rupiah) }\end{array}$ & $\begin{array}{c}\text { DPK } \\
\text { (Miliar Rupiah) }\end{array}$ & \multicolumn{1}{c}{$\begin{array}{c}\text { PYD } \\
\text { (Miliar Rupiah) }\end{array}$} \\
\hline 2007 & 36538 & 28012 & 27944 \\
2008 & 49555 & 36852 & 38195 \\
2009 & 66090 & 52271 & 46886 \\
2010 & 97519 & 76036 & 68181 \\
2011 & 145467 & 115415 & 102655 \\
2012 & 195018 & 147512 & 147505 \\
2013 & 242276 & 183534 & 184122 \\
\hline
\end{tabular}

Sumber : Statistik Perbankan Syariah, Bank Indonesia 2013

Perkembangan perbankan syariah menunjukkan peningkatan yang baik setiap tahunnya, namun market share perbankan syariah di Indonesia masih terbilang kecil. Menurut Islamic Financial Services Board (IFSB) dalam Islamic Financial Services Industry (IFSI) Stability Report 2014 Indonesia bersama dengan Banglades, Pakistan, dan Turki adalah negara - negara yang memiliki potensi signifikan dalam meningkatkan industri perbankan syariahnya. Market share di Indonesia sebesar 4.9\%, Bangladesh 16.8\%, Pakistan 9\%, dan Turki 5.3\%. Market share di Indonesia masih kecil dan tertinggal dibanding beberapa negara Islam maupun negara mayoritas berpenduduk Islam lainnya.

Bank Indonesia ingin mewujudkan sistem perbankan syariah yang modern, universal, dan terbuka bagi seluruh masyarakat Indonesia. Bank Indonesia telah membuat grand strategy untuk meningkatkan pasar perbankan syariah di Indonesia, dengan beberapa aspek strategis, salah satunya dengan pembentukan citra baru perbankan syariah nasional yang bersifat inklusif dan universal.

Jumlah penduduk Indonesia berdasarkan sensus penduduk yang dilakukan oleh Badan Pusat Statistik (BPS) tahun 2010 sebanyak 237641 326jiwa yang terdiri dari berbagai macam pemeluk agama. Selain agama Islam, Indonesia mengakui keberadaan lima agama lainnya yaitu Budha, Hindu, Kristen Protestan, Kristen Katholik, dan Kong $\mathrm{Hu} \mathrm{Cu}$. Berdasarkan hasil sensus yang dilakukan BPS pada tahun 2010 mengenai jumlah pemeluk agama, dapat dilihat pada Tabel 2.

Tabel 2 Komposisi Pemeluk Agama di Indonesia per Tahun 2010

\begin{tabular}{|c|c|c|}
\hline Agama & Jumlah (jiwa) & Persentase (\%) \\
\hline Islam & 207176162 & 87.18 \\
\hline Kristen & 16528513 & 6.96 \\
\hline Katolik & 6907873 & 2.91 \\
\hline
\end{tabular}




\begin{tabular}{lrc}
\hline Hindu & 4012116 & 1.69 \\
Buddha & 1703254 & 0.72 \\
Kong Hu Cu & 117091 & 0.05 \\
Lainnya & 299617 & 0.12 \\
Tidak terjawab & 139582 & 0.06 \\
Tidak ditanyakan & 757118 & 0.31 \\
Total & $\mathbf{2 3 7} \mathbf{6 4 1} \mathbf{3 2 6}$ & $\mathbf{1 0 0}$ \\
\hline
\end{tabular}

Sumber : BPS, 2012

Hal tersebut menggambarkan selain pasar nasabah muslim, bank syariah juga berpotensi melakukan ekspansi pada pasar nasabah non-muslim. Pasar industri perbankan domestik bersifat heterogen dengan berbagai kepercayaan yang dianut.

Daerah Khusus Ibukota (DKI) Jakarta adalah ibu kota Indonesia yang penduduknya terdiri dari berbagai macam suku, ras, dan agama. Menurut sensus yang dilakukan BPS mengenai jumlah penduduk menurut wilayah dan agama yang dianut, populasi penduduk DKI Jakarta adalah yang ke 6 tertinggi setelah Jawa Barat, Jawa Timur, Jawa Tengah, Sumatera Utara, dan Banten, yaitu sebanyak 9607787 jiwa.

Pesaing industri perbankan syariah di dalam negeri sendiri adalah perbankan konvensional. Perbankan syariah harus mampu bersaing dengan perbankan konvensional karena perbankan syariah memiliki keunggulan dibanding perbankan konvensional. Masyarakat non-muslim di Indonesia sebesar $12.82 \%$ tidak dengan begitu saja menjadi pangsa pasar untuk perbankan konvensional.

Tahun 2015 yang akan datang, Indonesia akan menghadapi Masyarakat Ekonomi Asean (MEA). Selain bank konvensional dalam negri, pesaing industri perbankan syariah akan bertambah, yaitu perbankan syariah dari luar. Potensi pasar domestik Indonesia akan sangat menarik bagi luar negri. Hal ini akan menjadi tantangan bagi Indonesia, terlebih menghadapi Malaysia tetangga terdekat Indonesia yang telah lebih dahulu mampu mengoptimalkan indutri perbankan syariahnya. Indonesia harus mampu menangani potensi industri perbankan syariah domestik, tidak hanya di pulau Jawa, juga di luar pulau Jawa yang banyak memeluk agama lain. Tidak hanya pasar muslim, juga pasar non-muslim yang berpotensi menyumbang DPK yang besar untuk perbankan syariah.

\section{TINJAUAN PUSTAKA}

\section{Bank Syariah}

Menurut UU Republik Indonesia No. 21 Tahun 2008 pasal 1 ayat 7 "bank syariah adalah bank yang menjalankan kegiatan usahanya berdasarkan prinsip syariah dan menurut jenisnya terdiri atas Bank Umum Syariah dan Bank Pembiayaan Rakyat Syariah. " Dan pasal 1 ayat 8 " Bank Umum Syariah adalah bank syariah yang dalam kegiatannya memberikan jasa dalam lalu lintas pembayaran."

Berbeda dengan bank konvensional yang menggunakan sistem bunga, bank syariah menggunakan sistem bagi hasil untuk menghindari riba.

\section{Pengertian Riba}

Larangan terhadap riba telah dijelaskan dalam Al-Qur'an dan hadis. Allah SWT menurunkan larangan mengenai riba melalui 4 tahapan.

1. QS. Ar-Ruum : 39 
"Dan sesuatu riba (tambahan) yang kamu berikan agar dia bertambah pada harta manusia, maka riba itu tidak menambah pada sisi Allah. Dan apa yang kamu berikan berupa zakat yang kamu maksudkan untuk mencapai keridhaan Allah, maka (yang berbuat demikian)itulah orang-orang yang melipatgandakan (pahalanya)".

2. QS. An-Nisaa : 160-161

"Maka disebabkan kezaliman orang-orang Yahudi, Kami haramkan atas mereka (memakan makanan) yang baik-baik (yang dahulunya) dihalalkan bagi mereka, dan karena mereka banyak menghalangi (manusia) dari jalan Allah, (160) dan disebabkan mereka memakan riba, padahal sesungguhnya mereka telah diharamkan daripadanya, dan karena mereka memakan harta benda orang dengan jalan yang batil. Kami telah menyediakan untuk orang -orang yang kafir di antara mereka itu siksa yang pedih (161)".

3. QS. Ali-Imran : 130

"Hai orang-orang yang beriman, janganlah kamu memakan riba dengan berlipat ganda dan bertakwalah kamu kepada Allah supaya kamu mendapat keberuntungan".

4. QS. Al-Baqarah : 275-281

"Orang-orang yang memakan riba tidak dapat berdiri melainkan seperti berdirinya orang yang kemasukan setan karena gila. Yang demikian itu karena mereka berkata bahwa jual beli itu sama dengan riba. Padahal Allah telah menghalalkan jual beli dan mengharamkan riba. Barang siapa mendapatkan peringatan dari Tuhannya, lalu dia berhenti, maka apa yang diperolehnya dahulu menjadi miliknya dan urusannya kepada Allah. Barang siapa mengulangi maka mereka penghuni neraka, mereka kekal didalamnya (275). Allah memusnahkan riba dan menyuburkan sedekah. Allah tidak suka setiap orang yang tetap dalam kekafiran dan bergelimpang dosa (276). Sungguh, orang yang beriman mengerjakan kebajikan, melaksanakan solat dan menunaikan zakat, mereka mendapat pahala di sisi Tuhannya. Tidak ada rasa takut pada mereka dan mereka tidak bersedih hati (277).Hai orang-orang yang beriman, bertakwalah kepada Allah dan tinggalkan sisa riba (yang belum dipungut) jika kamu orang-orang yang beriman (278). Maka jika kamu tidak mengerjakan (meninggalkan sisa riba), maka ketahuilah bahwa Allah dan Rasul-Nya akan memerangimu. Dan jika kamu bertobat (dari pengambilan riba), maka bagimu pokok hartamu; kamu tidak mengaiaya dan tidak (pula) dianiaya (279). Dan jika orang berhutang itu dalam kesulitan, maka berilah tenggang waktu sampai dia memperoleh kelapangan. Dan jika kamu menyedekahkan, itu lebih baik bagimu, jika kamu mengetahui (280). Dan takutlah pada hari ketika semua dikembalikan kepada Allah. Kemudian setiap orang diberi balasan yang sempurna sesuai dengan yang telah dilakukan, dan mereka tidak dizalimi (dirugikan) (281)”.

Rasulullah juga melarang riba dan segala aktivitas yang berkaitan. Beberapa hadis yang melarang riba adalah sebagai berikut dibawah ini.

Dari Jubair ra, Rasulullah saw mencela penerima dan pembayar bunga, orang yang mencatat begitu pula yang menyaksikan dimaksud. Beliau bersabda; "Mereka semua sama-sama berada dalam dosa" (HR. Muslim, Tirmizi dan Ahmad)

Dari Abu Said al Khudri ra, jangan melebih-lebihkan sau dengan yang lainnya; janganlah menjual perak untuk perak kecuali keduanya setara; dan jangan 
melebihkan satu dengan lainnya; dan jangan menjual sesuatu yang tidak tampak" (HR. Bukhari, Muslim. Tirmidzi, Nasa'i dan Ahmad)

Dari Ubada bin Sami ra, Nabi saw bersabda; "Emas untuk emas, perak untuk perak, gandum untuk gandum. Barang siapa membayar lebih atau menerima lebih dia telah berbuat riba, Pemberi dan penerima sama saja" (dalam dosa) ( HR. Muslim dan Ahmad)

Secara bahasa riba berarti tambahan, sedangkan menurut syariat yang dimaksud riba adalah menambah sesuatu yang khusus. Riba dibedakan menjadi 3, yaitu, riba fadhl, riba nasi'ah, dan riba qardh. Riba fadhl yang berarti jual beli barang yang sejenis dengan melebihkan nilai salah satunya. Riba nasi'ah adalah menjual barang dengan jenis-jenisnya sendiri atau jenis lain dengan kelebihan takaran atau timbangan dengan disyaratkan penundaan penerima dan pembayaran barang. Riba Qardh yaitu pemberian pinjaman sesuatu yang sah dipinjam sambil mensyaratkan bunga kepadanya sebagai imbalan pinjaman, misalnya rumah atau kendaraan. (Nawawi, 2009).

Berdasarkan Fatwa Majelis Ulama Indonesia Nomer 1 tahun 2004 "Bunga adalah tambahan yang dikenakan dalam transaksi pinjaman uang (al-qardh) yang di perhitungkan dari pokok pinjaman tanpa mempertimbangkan pemanfaatan/hasil pokok tersebut, berdasarkan tempo waktu, diperhitungkan secara pasti di muka, dan pada umumnya berdasarkan persentase. Riba adalah tambahan (ziyadah) tanpa imbalan yang terjadi karena penangguhan dalam pembayaran yang di perjanjikan sebelumnya, dan inilah yang disebut Riba Nasi'ah."

\section{Riba di Kalangan Non-Muslim}

Terdapat dalam teks Vedic India kuno (2000 - 1400 SM) bahwa pemungutan riba diartikan sebagai pemberian pinjaman dengan bunga, juga pada teks Sutra ( $700-100$ SM) dan Jatakas dalam Buddha ( 600 - 400 SM ) terdapat larangan meminjamkan uang dengan penambahan bunga bagi kasta Brahmana dan Kshatriya. Ajaran Yahudi menyatakan bahwa pemungutan bunga adalah yang dilarang dan hina. Sedangkan dalam ajaran Kristen, telah terjadi perdebatan panjang oleh lembaga-lembaga gereja kristen mengenai persoalan riba. Pada abad ke delapan Masehi, Gereja Khatolik Roma menganggap pemungutan riba sebagai tindakan kriminal. ( Mutasowifin, 2003)

Terdapat beberapa larangan riba dalam teks Yahudi seperti yang dikutip oleh Iqbal dan Mirakhor (2008).

"Jika engkau meminjamkan uang kepada salah seorang dari umat-Ku, orang yang miskin di antaramu, maka janganlah engkau berlaku sebagai seorang penagih utang terhadap dia: janganlah kamu bebankan bunga uang kepadanya”. (Keluaran 22:25 )

"Janganlah engkau mengambil bunga uang atau riba daripadanya, melainkan engkau harus takut akan Allahmu, supaya saudaramu dapat hidup diantaramu”. (Imamat 25:36)

"Janganlah engkau memberi uangmu kepadanya dengan meminta bunga, juga makananmu janganlah kau berikan dengan meminta riba”. (Imamat 25:37)

"Janganlah engkau membungakan kepada saudaramu, baik uang maupun bahan makanan atau apa pun yang dapat dibungakan". (Ulangan 23:19)

Dikutip dari Iqbal dan Mirakhor (2008), sejak awal sejarah kristen, membebankan bunga merupakan hal yang dikutuk, hingga pada akhir abad ke 13 pengaruh sekuler mulai 
meningkat akibat dari praktek pembebanan bunga yang mendapat toleransi walaupun tetap dilarang oleh gereja. Beberapa larangan bunga terdapat dalam Injil.

"Barang siapa yang memperbanyak hartanya dengan bunga dan dengan cara tidak adil, mak ia menyakiti orang miskin”. (Amsal 28:8)

"Barang siapa yang tidak memungut bunga uang atau mengambil riba, menjauhkan diri dari kecurangan, maka ia telah menjalankan penilaian yang benardi antara manusia dengan manusia". (Yezhekiel 18:8)

\section{Penelitian Terdahulu}

Penelitian yang dillakukan oleh Machmudah (2009) yang berjudul Faktor-faktor yang Mempengaruhi Minat Nasabah Non-Muslim Menjadi Nasabah di Bank Syariah (Studi Pada Bank CIMB Niaga Syariah Cabang Semarang) menggunakan metode regresi linier berganda dan uji hipotesa. Hasil yang diperoleh adalah variabel lokasi, pelayanan, religius stimuli, reputasi, profit sharing, dan promosi berpengaruh positif terhadap minat nasabah non-muslim menjadi nasabah bank syariah, sedangkan faktor yang paling berpengaruh terhadap minat nasabah non-muslim menjadi nasabah bank syariah adalah variabel profit sharing.

Penelitian oleh Humaemah (2006) mengenai Faktor-faktor yang Mempengaruhi Etnis Cina Non-Muslim Menjadi Nasabah Bank Syariah ( Studi kasus : PT Bank Syariah Mega Indonesia) menggunakan analisis faktor sebagai metode analisis data. Hasil yang diperoleh adalah faktor dominan yang mempengaruhi keputusan etnis China non-muslim menjadi nasabah di Bank Syariah Mega Indonesia adalah faktor promosi, yang terdiri dari enam atribut, yaitu promosi melalui iklan di media massa (tv dan koran), promosi di mallmall, promosi lebih dikemas lebih kreatif dan menarik, sosialisasi, promosi melalui figur seorang tokoh, promosi awal atas suatu produk bank syariah dengan bahasa komunikasi tanpa menggunakan simbol islam.

Penelitian yang dilakukan oleh Sudin et al(1994) yang berjudul Bank Patronage Factors of Muslim and Non-Muslim Customers menggunakan Principal Component Analysis sebagai metode pengolahan data. Friendliness of bank personelmenjadi faktor terpenting yang berada pada rank pertama bagi nasabah non-muslim, tetapi menjadi rank ketiga bagi nasabah muslim. Bagi nasabah muslim, faktor terpenting yang berada di rank pertama adalah fast and efficient service, yang bagi nasabah non-muslim berada di rank kedua.

Penelitian oleh Hasan, Syed et al (2012) berjudul Consumer Criteria for the Selection of anIslamic Bank: Evidence from Pakistan. Menggunakan t-test dan hasil yang didapatkan adalah faktor high profit and low service, religious motives, service quality berpengaruh pada bank islam oleh nasabah, dan faktor high profit and low servicemenjadi faktor yang paling memengaruhi.

Amirudin (2010) dalam penelitiannya yang berjudul Studi Pereferensi dan Segmentasi Pasar BRI Syariah (Kasus Masyarakat Kota Bogor), menggunakan metode regresi logistik biner, hasil yang didapat adalah faktor-faktor yang mempengaruhi potensi masyarakat dalam mengadopsi BRISyariah adalah pendidikan, pendapat yang mengatakan bunga bank bertentangan dengan agama yang dianut, pendapat yang mengatakan bagi hasil dapat diterapkan, pendapat yang mengatakan bagi hasil lebih diminati, pertimbangan memilih bank karena ATM dan popularitas. Segmen pasar BRISyariah cenderung diminati oleh orang yang berpendidikan rendah. 
Ziliwu (2008) meneliti mengenai Analisis Faktor-faktor yang Mempengaruhi Nasabah dalam Menggunakan Tabungan Syariah Plus pada Bank BNI Syariah di Jakarta. Metode yang digunakan adalah Ordinary Least Square(OLS). Hasil yang didapat adalah faktorfaktor yang memengaruhi nasabah dalam menggunakan tabungan syariah plus pada Bank BNI di Jakarta adalah variabel ekonomi, pelayanan, dan motivasi.

Penelitian yang dilakukan Setiasih (2011) berjudul Analisis Persepsi, Preferensi, Sikap dan Perilaku Dosen Terhadap Perbankan Syariah (Studi Kasus pada Dosen Fakultas Syariah IAIN Walisongo Semarang ), alat analisis yang digunakan adalah analisis regresi. Hasil yang didapatkan adalah variabel persepsi tidak mempunyai pengaruh yang signifikan terhadap sikap, variabel preferensi mempunyai pengaruh yang signifikan terhadap sikap, dan variabel sikap mempunyai pengaruh yang signifikan terhadap perilaku.

\section{METODE}

\section{Lokasi dan Waktu Penelitian}

Penelitian ini dilakukan di beberapa bank syariah untuk responden nasabah non-muslim bank syariah, yaitu Bank Syariah Mandiri (BSM), Bank Negara Indonesia Syariah (BNI Syariah), dan Bank Rakyat Indonesia Syariah (BRIS), sementara untuk nasabah nonmuslim bank konvensional, penelitian di lakukan di beberapa pusat perbelanjaan dan menyebarkan kuesioner online. Penelitian ini dilakukan dari bulan Februari 2014 hingga Juni 2014. Penelitian ini dilakukan di DKI Jakarta, wilayah Jakarta dianggap cocok untuk penelitian ini, karena Jakarta memiliki penduduk yang sangat banyak dan terdiri dari berbagai suku, ras, dan agama yang heterogen, agar penelitian dapat mencakup seluruh atau sebagian besar agama yang dianut penduduk Indonesia dari 6 agama yang diakui di Indonesia.

\section{Jenis dan Sumber Data}

Data yang digunakan dalam penelitian ini adalah data primer dan sekunder. Data primer diperoleh dari pengisian kuesioner oleh nasabah non-muslim BSM, BNI Syariah, BRIS dan nasabah non-muslim bank konvensional. Data sekunder diperlukan untuk melengkapi dan mendukung berbagai teori yang dibutuhkan dalam penelitian ini. Data sekunder didapatkan dari berbagai studi pustaka dan literatur, baik dari buku, jurnal, penelitian terdahulu maupun referensi lain baik dalam media cetak maupun internet.

\section{Metode Pengumpulan Data}

Sampel dalam penelitian ini diambil dengan tekhnik nonprobability sampling, dengan metode purposive sampling. Sample yang diambil adalah nasabah bank syariah dan nasabah bank konvensional yang memenuhi kriteria beragama selain Islam.

Menentukan ukuran sampel, berdasarkan Gay dan Diehl (1992) dalam Rahayu (2005) untuk penelitian kausal perbandingan, sampel yang digunakan sebanyak 30 responden per grup. Berdasarkan Roscoe (1975) dalam Rahayu (2005) ukuran sampel pada setiap penelitian harus berkisar antara 30 dan 500. Apabila sampel akan dipecah menjadi beberapa bagian, maka minimum ukuran sampel sebanyak 30 untuk tiap bagian yang diperlukan. Responden yang digunakan dalam penelitian ini sebanyak 100 responden yang terdiri dari 50 nasabah non-muslim bank syariah dan 50 nasabah non-muslim bank konvensional. 
Pengumpulan data dalam penelitian ini terkendala dengan terbatasnya mengakses data nasabah yang beragama non-muslim dan sulitnya bertemu dengan nasabah karena tidak banyak nasabah yang sering datang ke kantor cabang.

\section{Metode Pengolahan dan Analisis Data}

Metode analisis yang digunakan dalam penelitian ini adalah analisis deskriptif dan regresi logistik biner menggunakan software SPSS 16 untuk pengolahan data dan Microsoft Excel 2010 untuk tabulasi data.

\section{Analisis Deskriptif}

Analisis deskripsi akan digunakan untuk menjelaskan karakteristik responden dan kecenderungan nasabah non-muslim terhadap bank syariah. Data kuesioner yang telah disebar kepada responden dijelaskan dalam bentuk tabel dan gambar grafik.

\section{Regresi Logistik}

Metode analisis data yang digunakan untuk melihat faktor yang mempengaruhi nasbah non-muslim dalam menggunakan jasa bank syariah adalah dengan menggunakan regresi logistik. Regresi pada variabel tak bebas yang merupakan dummy bernilai 0 atau 1 dengan pendekatan logit model. Berikut model logit yang digunakan dalam penelitian ini :

$P_{i}=\frac{e^{\alpha+\beta X_{1}+\beta X_{2}+\beta X_{3}+\beta X_{4}+\beta X_{5}+\beta X_{6}}}{\left[1+e^{\left.\alpha+\beta X_{1}+\beta X_{2}+\beta X_{3}+\beta X_{4}+\beta X_{5}+\beta X_{6}\right]}\right.}$ (1)

Keterangan :

$\mathrm{P}_{\mathrm{i}}=$ Keputusan nasabah non-muslim menggunakan jasa bank syariah bank syariah (1 jika menggunakan bank syariah, 0 jika tidak menggunakan bank syariah)

$\alpha \quad=$ Intersept

$\beta=$ Parameter peubah $\mathrm{X}_{\mathrm{i}}$

$\mathrm{X}_{1} \quad=$ Lokasi

$\mathrm{X}_{2} \quad=$ Pelayanan

$\mathrm{X}_{3}=$ Keuntungan administratif

$\mathrm{X}_{4}=$ Promosi

$\mathrm{X}_{5} \quad=$ Stimulan religi

$\mathrm{X}_{6}=$ Produk

Odd ratio $=\frac{P_{i}}{1-P_{i}}$ 
Odd ratiomerupakan rasio antara probabilitas untuk terjadinya kejadian 1 (menggunakan bank syariah) terhadap probabilitas untuk terjadinya kejadian 0 (tidak menggunakan bank syariah).

Penilain atas kecenderungan nasabah terhadap bank syariah dinilai dengan menggunkaan skala likert. Menurut Suliyanti (2005), skala likert digunakan untuk mengukur sikap, pendapat, dan persepsi seseorang mengenai fenomena sosial. Banyaknya pilihan respon yang digunakan terdiri dari 5 pilihan respon, yaitu

$$
\begin{aligned}
& 1=\text { Sangat Tidak Setuju (STS) } \\
& 2=\text { Tidak Setuju (TS) } \\
& 3=\text { Ragu-ragu (R) } \\
& 4=\text { Setuju (S) } \\
& 5=\text { Sangat Setuju (SS) }
\end{aligned}
$$

\section{Definisi Operasional}

Variabel yang digunakan dalam penelitian ini dan definisi operasionalnya diantaranya sebagai berikut,

1. Lokasi yang dimaksud adalah lokasi kantor pusat bank, cabang utama bank, cabang pembantu bank, kantor kas, mesin Anjungan Tunai Mandiri (ATM) serta layout gedung dan ruang kantor.

2. Pelayanan dari pihak bank kepada nasabah adalah bagian dari etiket pihak bank kepada nasabah. Menurut Kasmir (2005) etiket adalah tindakan mengatur tingkah laku atau perilaku manusia dengan masyarakat. Pelayanan dalam penelitian ini berkaitan dengan sikap dan perilaku, penampilan, kinerja staff dan menejemen bank.

3. Keuntungan administratif. Bagi bank dengan sistem konvensional, harga adalah bunga, biaya administrasi, dan biaya lainnya, namun untuk bank dengan sistem syariah, bukan bunga yang digunakan, melainkan bagi hasil (Kasmir, 2005). Keuntungan administratif yang digunakan dalam penelitian ini meliputi nisbah bagi hasil bank syariah dibandingkan dengan bunga pada bank konvensional serta biaya administrasi.

4. Promosi secara garis besar terdapat 4 macam sarana promosi yang dapat digunakan oleh perbankan diantaranya periklanan, promosi penjualan, publisitas, dan penjualan pribadi (Kasmir, 2005). Penelitian ini menggunakan indikator promosi melalui periklanan serta promosi penjualan.

5. Stimulan religi adalah faktor pengetahuan keagamaan yang mendorong seseorang untuk melakukan tindakan ekonomi (Machudah, 2009). Penelitian ini menggunakan indikator pengetahuan nasabah mengenai riba dan pandangan agama yang dipeluk oleh nasabah mengenai riba.

6. Produk bank terdiri dari produk penghimpunan dana, penyaluran dana, dan pemberian jasa-jasa lainnya seperti transfer, kliring, dan lainnya. (Kasmir, 2005). Produk bank konvensional dan bank syariah pada dasarnya serupa tetapi menggunakan prinsip yang berbeda. 


\section{HASIL DAN PEMBAHASAN}

\section{Karakteristik Responden}

Responden dalam penelitian sebanyak 100 nasabah non-muslim, yang terdiri dari 50 nasabah non-muslim pada bank syariah dan 50 nasabah non-muslim pada bank konvensional.

\section{Jenis Kelamin}

Responden nasabah non-muslim bank syariah memiliki lebih banyak responden berjenis kelamin laki-laki sebanyak 56\% dari 50 nasabah, sedangkan pada kelompok responden nasabah non-muslim bank konvensional memiliki lebih banyak responden berjenis kelamin perempuan sebanyak $74 \%$ dari 50 nasabah.

Tabel 3 Karakteristik Responden Berdasarkan Jenis Kelamin

\begin{tabular}{lrc}
\hline \multicolumn{1}{c}{ Jenis Kelamin } & Jumlah Nasabah & Persentase (\%) \\
\hline Nasabah Non-Muslim Bank Syariah & & \\
Laki-Laki & 28 & 56 \\
Perempuan & 22 & 44 \\
Total & 50 & 100 \\
Nasabah Non-Muslim Bank Konvensional & \\
Laki-Laki & 13 & 26 \\
Perempuan & 37 & 74 \\
Total & 50 & 100 \\
& & \\
\hline
\end{tabular}

\section{Usia}

Karakteristik responden berdasarkan usia pada responden nasabah non-muslim bank syariah mayoritas memiliki usia diatas 40 tahun yaitu sebanyak $46 \%$ dari 50 nasabah. Responden nasabah non-muslim bank konvensional mayoritas berusia sekitar 17-29 tahun sebanyak $76 \%$ dari 50.

Tabel 4 Karakteristik Responden Berdasarkan Usia

\begin{tabular}{lrc}
\hline \multicolumn{1}{c}{ Usia (tahun) } & Jumlah Nasabah & Persentase (\%) \\
\hline Nasabah Non-Muslim Bank Syariah & & \\
$17-29$ & 9 & 18 \\
$30-40$ & 18 & 36 \\
$>40$ & 23 & 46 \\
Total & 50 & 100 \\
Nasabah Non-Muslim Bank Konvensional & \\
$17-29$ & 38 & 76 \\
$30-40$ & 10 & 20 \\
$>40$ & 2 & 4 \\
Total & 50 & 100 \\
& & \\
\hline
\end{tabular}

Agama 
Karakteristik responden berdasarkan agama yang dianut pada responden nasabah nonmuslim bank syariah mayoritas adalah pemeluk agama Kristen protestan dan Budha dengan masing-masing persentase $30 \%$, sementara responden nasabah non-muslim bank konvensional mayoritasnya adalah pemeluk agama Kristen protestan dengan persentase $52 \%$.

Tabel 5 Karakteristik Responden Berdasarkan Agama

\begin{tabular}{lcc}
\hline \multicolumn{1}{c}{ Agama } & Jumlah Nasabah & Persentase (\%) \\
\hline Nasabah Non-Muslim Bank Syariah & & \\
Kong Hu Cu & 4 & 8 \\
Kristen Katolik & 16 & 32 \\
Kristen Protestan & 15 & 30 \\
Budha & 15 & 30 \\
Total & 50 & 100 \\
Nasabah Non-Muslim Bank Konvensional & \\
Kong Hu Cu & 3 & 6 \\
Kristen Katolik & 11 & 22 \\
Kristen Protestan & 26 & 52 \\
Hindu & 2 & 4 \\
Budha & 8 & 16 \\
Total & 50 & 100 \\
& & \\
\hline
\end{tabular}

\section{Pendidikan Terakhir}

Responden nasabah non-muslim bank syariah mayoritas merupakan lulusan sarjana strata 1 sebesar 54\%, begitu pula responden nasabah non-muslim bank konvensional yang mayoritas lulusan sarjana strata 1 sebanyak $46 \%$.

Tabel 6 Karakteristik Responden Berdasarkan Pendidikan Terakhir

\begin{tabular}{|c|c|c|}
\hline Pendidikan Terakhir & Jumlah Nasabah & Persentase (\%) \\
\hline \multicolumn{3}{|c|}{ Nasabah Non-Muslim Bank Syariah } \\
\hline SMP / sederajat & 1 & 2 \\
\hline SMA / sederajat & 12 & 24 \\
\hline D3 & 9 & 28 \\
\hline $\mathrm{S} 1$ & 27 & 54 \\
\hline S3 & 1 & 2 \\
\hline Total & 50 & 100 \\
\hline \multicolumn{3}{|c|}{ Nasabah Non-Muslim Bank Konvensional } \\
\hline SMP / sederajat & 2 & 4 \\
\hline SMA /sederajat & 17 & 34 \\
\hline D3 & 7 & 14 \\
\hline $\mathrm{S} 1$ & 23 & 46 \\
\hline $\mathrm{S} 2$ & 1 & 2 \\
\hline Total & 50 & 100 \\
\hline
\end{tabular}

\section{Pekerjaan}


Tabel 7 mengenai karakteristik responden berdasarkan pekerjaan, mayoritas responden nasabah bank syariah merupakan wiraswasta, yaitu sebanyak 50\%, sedangkan responden nasabah non-muslim bank konvensional mayoritas merupakan mahasiswa/pelajar, yaitu sebanyak $40 \%$.

Tabel 7 Karakteristik Responden Berdasarkan Pekerjaan

\begin{tabular}{lcc}
\hline \multicolumn{1}{c}{ Pekerjaan } & Jumlah Nasabah & Persentase (\%) \\
\hline Nasabah Non-Muslim Bank Syariah & 3 & 6 \\
PNS & 20 & 40 \\
Karyawan Swasta & 25 & 50 \\
Wiraswasta & 21 & 4 \\
Lainnya & 50 & 100 \\
Total & 13 & \\
Nasabah Non-Muslim Bank Konvensional & 26 \\
Karyawan Swasta & 12 & 24 \\
Wiraswasta & 20 & 40 \\
Mahasiswa/Pelajar & 5 & 10 \\
Lainnya & 50 & 100 \\
Total & & \\
\end{tabular}

\section{Pendapatan}

Mayoritas responden nasabah non-muslim bank syariah memiliki pendapatan diatas Rp 5 000 000,00 perbulannya. Responden nasabah non-muslim bank konvensional mayoritas memiliki pendapatan sekitar Rp 3000001,00 - Rp 5000 001,00 perbulannya.

Tabel 8 Karakteristik Responden Berdasarkan Pendapatan perBulan

\begin{tabular}{lcc}
\hline \multicolumn{1}{c}{ Pendapatan per Bulan } & Jumlah Nasabah & Persentase (\%) \\
\hline Nasabah Non-Muslim Bank Syariah & & 6 \\
Rp 1.500.001,00 - Rp 3.000.000,00 & 3 & 38 \\
Rp 3.000.001,00 - Rp 5.000.001,00 & 19 & 56 \\
> Rp 5.000.000,00 & 28 & 100 \\
Total & 50 & \\
Nasabah Non-Muslim Bank Konvensional & & 10 \\
> Rp 500.000,00 & 5 & 16 \\
Rp 500.000,00-Rp 1.500.000,00 & 14 & 28 \\
Rp 1.500.001,00-Rp 3.000.000,00 & 16 & 32 \\
Rp 3.000.001,00 - Rp 5.000.001,00 & 7 & 14 \\
> Rp 5.000.000,00 & 50 & 100 \\
Total & & \\
\end{tabular}

\section{Kecenderungan Nasabah Non-Muslim terhadap Bank Syariah}

Gambar 1 memaparkan presentase sumber informasi nasabah non-muslim bank syariah mengenai bank syariah. Responden nasabah non-muslim bank syariah mayoritas mendapatkan informasi mengenai bank syariah melalui teman/orang lain dan juga internet, yaitu masing-masing 23\%. Hal ini dikarenakan nasabah cenderung lebih memercayai rekomendasi dari teman yang sering mereka temui. Intensitas masyarakat dalam mengakses internet belakangan waktu ini sangat tinggi, hampir setiap hari masyarakat Jakarta mengakses internet, hal ini juga yang memengaruhi nasabah non- 
muslim bank syariah dalam mendapatkan informasi mengenai bank syariah. Presentase sumber informasi nasabah non-muslim bank syariah terhadap bank syariah yang terkecil adalah informasi yang di dapat dari iklan di mall yang hanya $1 \%$. Hal ini karena iklan bank syariah di mall belum begitu banyak, dan masyarakat yang pergi ke mall lebih berkonsentrasi untuk berbelanja atau mengunjungi toko-toko produk yang mereka inginkan sehingga cenderung tidak memerhatikan iklan bank syariah.

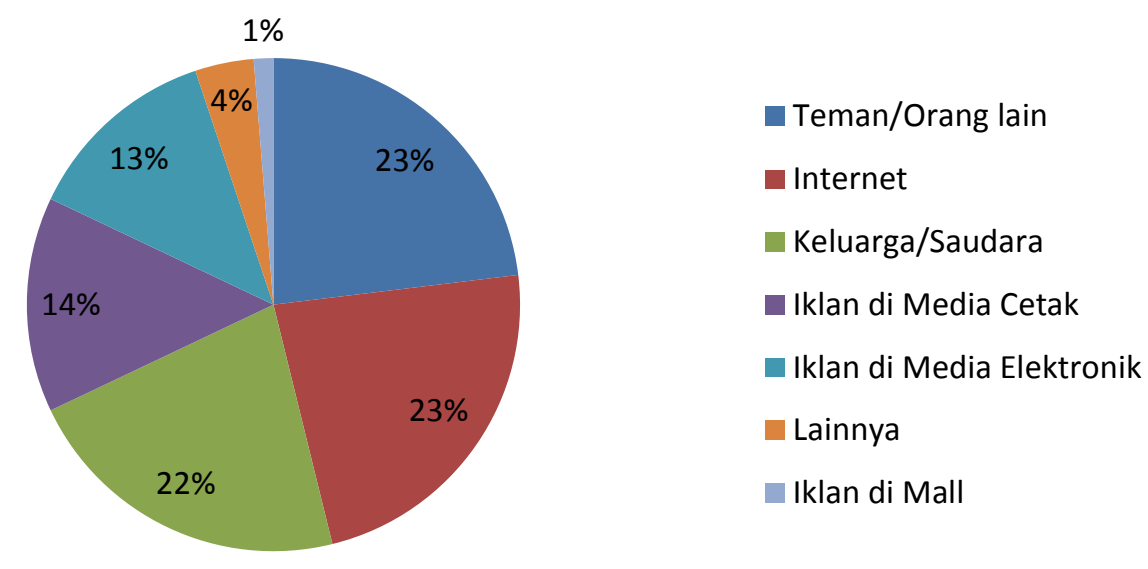

Gambar 1 Sumber Informasi nasabah non-muslim bank syariah

Responden nasabah non-muslim bank syariah sebesar 68\% dari 50 nasabah mengakui bank syariah lebih unggul dibanding bank konvensional seperti terlihat pada gambar 2 . Alasan terbanyak yang dipilih nasabah non-muslim bank syariah dapat dilihat di gambar 3.

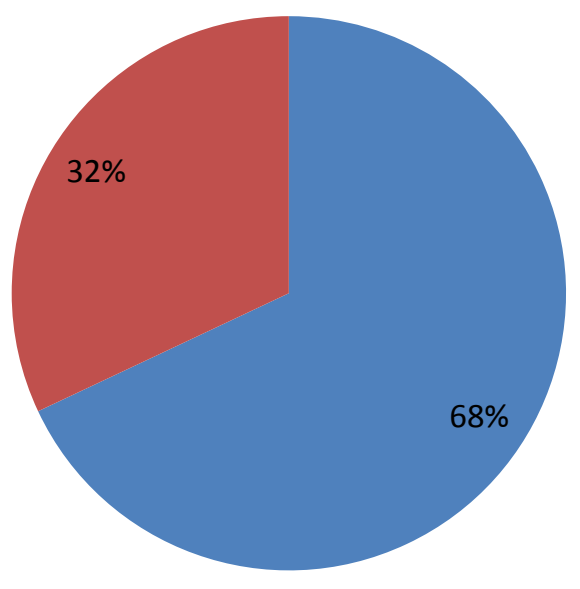

Bank syariah lebih unggul

Bank konvensional lebih unggul 
Gambar 2 Pendapat nasabah non-muslim bank syariah mengenai keunggulan bank syariah

Gambar 3 menjelaskan persentase alasan terbanyak mengenai nasabah non-muslim bank syariah yang menganggap bank syariah lebih unggul dibanding bank konvensional. Hal itu berhubungan dengan 37\% nasabah memiliki alasan bahwa produk bank syariah lebih transparan.Contohnya pada produk pembiayaan bank syariah, setiap bulannya pihak bank akan kembali menjelaskan kepada nasabah mengenai keuntungan bagi hasil yang mereka peroleh, dan kewajiban yang harus mereka bayarkan, serta rincian lainnya mengenai kerjasama yang mereka lakukan.

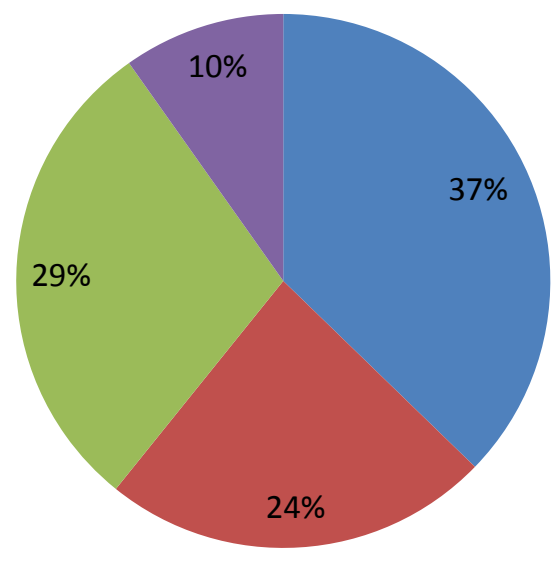

\author{
- Produk bank syariah lebih \\ transparan \\ Bagi hasil lebih adil \\ dibanding bunga \\ produk bank syariah \\ mementingkan \\ kesejahteraan nasabahnya \\ - Lainnya
}

Gambar 3 Alasan bank syariah dianggap lebih unggul

Nasabah non-muslim bank syariah dianggap bagian dari floating mass. Nasabah nonmuslim bank syariah yang telah menggunakan jasa bank syariah, sebagian besar juga menggunakan jasa bank konvensional.Sebanyak 96\% dari 50 nasabah non-muslim bank syariah juga merupakan nasbah bank konvensional atau sebanyak 48 nasabah non-muslim bank syariah juga menjadi nasabah bank konvensional, dan hanya sebanyak 2 nasabah yang tidak menjadi nasabah di bank konvensional. 


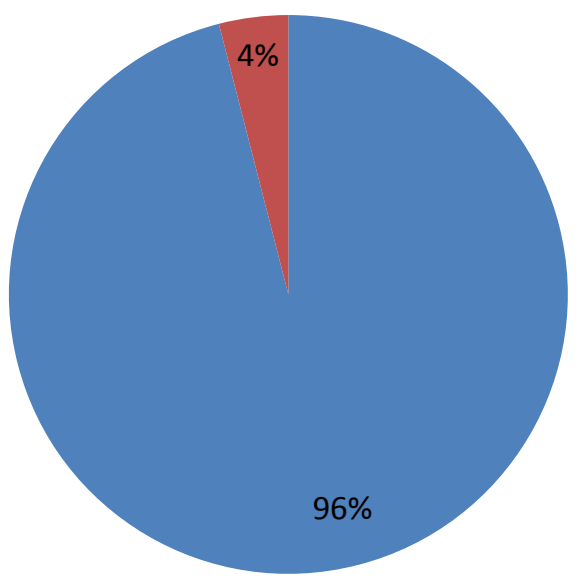

nasabah non-muslim bank syariah yang menjadi nasabah di bank konvensonal

Nasabah non-muslim bank syariah yang tidak menjadi nasabah bank konvensional

Gambar 4 Persentase nasabah non-muslim bank syariah yang menjadi nasabah bank konvensional

Alasan responden menjadi nasabah di bank konvensional ternyata di dominasi oleh lokasi kantor cabang dan ATM yang banyak dan mudah ditemukan, yaitu sebesar $30 \%$. Kemudahan mereka mengakses kantor cabang sangat membantu dalam mengatasi berbagai urusan yang mengharuskan mereka mendatangi kantor cabang dan terutama kemudahan menemukan ATM sangat membantu keseharian mereka dalam membayar tagihan dan mendapatkan uang tunai sewaktu-waktu. Alasan terbanyak kedua adalah karena nama bank yang sudah besar dan terpercaya, yaitu sebesar 25\%. Banyak nasabah non-muslim bank syariah yang mengaku telah lama menjadi nasabah bank konvensional sejak semula karena sering mendengar nama bank tersebut dan sudah langsung percaya.

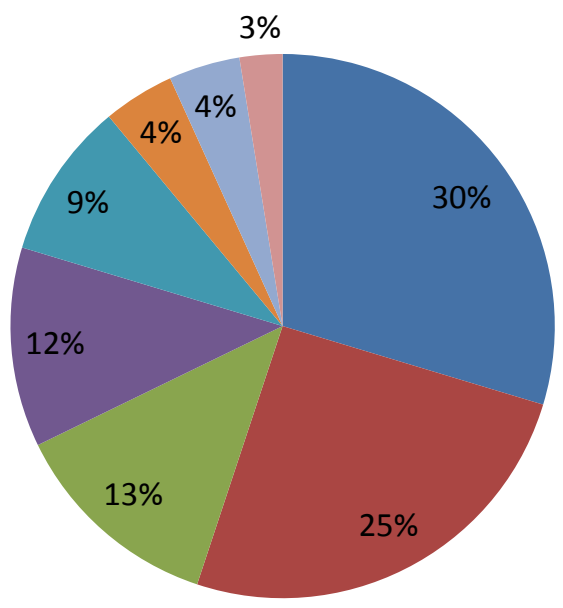

- Lokasi kantor cabang dan ATM banyak dan mudah ditemukan - Nama bank yang sudah besar dan terpercaya

Pelayanan staff bank yang ramah dan cekatan

Menejemen bank yang profesional

Transfer gaji dari kantor

Tingkat bunga yang lebih tinggi dari bagi hasil

Menawarkan hadiah yang menarik

Biaya administrasi rendah

Gambar 5 Alasan nasabah non-muslim bank syariah menggunakan bank konvensional

Faktor yang mempengaruhi nasabah non-muslim dalam menggunakan jasa bank syariah 
Bank syariah yang menjalankan aktifitas perbankannya berdasarkan syariah islam tidak berarti dikhuskan hanya untuk umat muslim, jasa bank syariah juga dapat digunakan oleh masyarakat non-muslim. Analisis faktor-faktor yang memengaruhi nasabah non-muslim dalam menggunakan jasa bank syariah dalam penelitian ini diolah dengan metode regresi logistik biner. Hasil olahan data dalam penelitian ini telah memenuhi asumsi multikolinearitas. Hasil olahan regresi logistik biner dapat dilihat pada paparan dibawah ini.

Tabel 9 Hasil Prediksi Ketepatan Model

\begin{tabular}{|c|c|c|c|}
\hline \multirow{3}{*}{ Observasi } & \multicolumn{3}{|c|}{ Prediksi } \\
\hline & \multicolumn{2}{|c|}{$\mathrm{Y}$} & \multirow{2}{*}{$\begin{array}{c}\text { Percentage } \\
\text { Correct }\end{array}$} \\
\hline & $\begin{array}{l}\text { Nasabah Non-Muslim } \\
\text { Bank Konvensional }\end{array}$ & $\begin{array}{l}\text { Nasabah Non- } \\
\text { Muslim Bank } \\
\text { Syariah }\end{array}$ & \\
\hline $\begin{array}{l}\text { Tidak menggunakan } \\
\text { jasa bank syariah }\end{array}$ & 40 & 10 & 80.0 \\
\hline $\begin{array}{l}\text { Menggunakan jasa } \\
\text { bank syariah }\end{array}$ & 3 & 47 & 94.0 \\
\hline Overall percentage & & & 87.00 \\
\hline
\end{tabular}

Hasil persentase ketepatan klasifikasi diatas menunjukan bahwa model mampu mengklasifikasikan nasabah non-muslim yang tidak menggunakan jasa bank syariah sebesar $80 \%$ dan model mampu mengklasifikasikan nasabah non-muslim yang menggunakan jasa bank syariah sebesar $94 \%$. Nilai overall percentage yang diperoleh adalah sebesar $87 \%$. Hal ini menunjukkan bahwa dalam 100 observasi, model mampu mengklasifikasi 87 observasi dengan tepat.

Tabel 10 Hosmer and Lemeshow Test

\begin{tabular}{llll}
\hline Step & Chi-Square & df & Sig \\
\hline 1 & 14.124 & 8 & .079
\end{tabular}

Hasil uji Hosmer and Lemeshow menunjukkan hasil Chi-Square 14.124 dengan P-Value 0.079 yang berarti lebih besar dari alpha $5 \%$. Hal ini berarti model regresi logistik yang digunakan telah cukup mampu menjelaskan faktor-faktor yang memengaruhi nasabah non-muslim dalam menggunakan jasa bank syariah dengan keyakinan $95 \%$.

Tabel 11 Uji Nagelkerke R-Square

\begin{tabular}{lllllll}
\hline Step & -2 Likelihood & $\begin{array}{l}\text { Cox \& } \\
\text { square }\end{array}$ & Snell & $\begin{array}{l}\text { Nagelkerke } \\
\text { Square }\end{array}$ & $R-$ \\
\hline 1 & 71.431 & .489 & & .652 &
\end{tabular}

Hasil uji Nagelkerke R-Square menunjukkan nilai Nagalkerke R-Square sebesar 0.652, maka varians dari keputusan seorang nasabah non-muslim untuk menggunakan jasa bank syariah yang dapat dijelaskan oleh model adalah sebesar $65,2 \%$, namun nilai ini hanya pendekatan saja, karena pada regresi logistik, koefisien determinasi tidak dapat dihitung seperti pada regresi linier, sehingga dalam regresi logistik yang perlu lebih diperhatikan adalah seberapa banyak model dapat memprediksi dengan tepat seperti yang dapat dilihat dalam uji Homesr and Lemeshow. 
Tabel 12 Faktor-faktor yang Memengaruhi Nasabah Non-Muslim terhadap Bank Syariah

\begin{tabular}{lllc}
\hline Variabel & Parameter & P-Value & Odd Ratio \\
\hline Lokasi & 0.372 & $0.060^{*}$ & 1.450 \\
Pelayanan & -0.116 & 0.544 & 0.890 \\
Keuntungan & 1.915 & $0.001^{* *}$ & 6.790 \\
administratif & & & \\
Promosi & 0.232 & 0.168 & 1.261 \\
Stimulan Religi & 0.986 & $0.001^{* *}$ & 2.679 \\
Produk & 0.238 & 0.458 & 1.268 \\
Konstanta & -19.181 & 0.000 & 0.000 \\
\hline Ket & $*$ signifikan & &
\end{tabular}

:* signifikan pada $\alpha 10 \%$

Estimasi persamaan model logit yang terbentuk adalah

$$
P_{i}=\frac{\exp \left(-19.181+0.372 X_{1 i}+1.915 X_{2 i}+0.986 X_{3 i}\right)}{1+\exp \left(-19.181+0.372 X_{1 i}+1.915 X_{2 i}+0.986 X_{3 i}\right)}
$$

Keterangan :

$\mathrm{P}_{\mathrm{i}}=$ Keputusan nasabah non-muslim menggunakan jasa bank syariah (1 jika menggunakan jasa bank syariah, 0 jika tidak menggunakan bank syariah)

$\mathrm{X}_{1}=$ Lokasi

$\mathrm{X}_{2}=$ Keuntungan administratif

$\mathrm{X}_{3}=$ Stimulan religi

Tabel 12 menunjukan variabel lokasi berpengaruh pada taraf nyara 10\% dan variabel keuntungan administratif serta stimulan religi berpengaruh pada taraf nyata $5 \%$. Sedangkan variabel pelayanan, promosi, dan produk tidak berpengaruh nyata pada penelitian ini.

Variabel lokasi memiliki koefisien bertanda positif dengan odd ratio 1.450 . Hal ini berarti jika lokasi bank syariah semakin dekat dengan kantor cabang dan ATM yang mudah dan banyak ditemukan, makin besar peluang nasabah non-muslim berminat terhadap bank syariah lebih tinggi yaitu sebesar 1.450 kali. Hal ini dikarenakan penentuan lokasi bisnis yang strategis mampu memengaruhi aktifitas bank sebagai penghimpunan dan penyaluran dana masyarakat. Beberapa hal yang menjadi pertimbangan dalam menentukan lokasi suatu bank diantaranya, dekat dengan kawasan industri atau pabrik, dekat dengan perkantoran, dekat dengan pasar, dekat dengan perumahan atau masyarakat, dan mempertimbangkan jumlah pesaing yang ada di suatu lokasi ( Al-Arif, 2010)

Variabel keuntungan administratif memiliki koefisien bertanda positif dengan nilaiodd ratio 6.790. Apabila biaya pada bank syariah semakin rendah dan memberikan bagi hasil yang tinggi, maka besar peluang nasabah non-muslim berminat terhadap bank syariah lebih besar 6.790 kali.

Variabel stimulan religi memiliki tanda koefisien positif. Dapat diinterpretasikan jika semakin religius responden, maka semakin besar peluang nasabah non-muslim berminat 
terhadap bank syariah sebesar 2.679 kali jika dibandingkan responden yang kurang religius. Hal ini sesuai dengan larangan riba yang juga dilarang dalam kepercayaan lain. Teks Vedic India kuno (2000-1400 SM) menjelaskan pemungutan riba diartikan sebagai pemberian pinjaman dengan bunga.Larangan meminjamkan uang dengan penambahan bunga bagi kasta Brahmana dan Kashatriya pada teks Sutra (700-100 SM) dan Jatakas dalam Buddha (600-400 SM).Ajaran Yahudi menyatakan bahwa pemungutan bunga adalah dilarang dan hina. Abad ke-8 Masehi, Gereja Khatolik Roma menganggap pemungutan riba sebagai tindakan kriminal ( Mutasowifin, 2003)

Variabel pelayanan memiliki parameter negatif dengan odd ratio 0.890 , namun variabel pelayanan tidak berpengaruh nyata terhadap penelitian ini. Hal ini bisa terjadi karena responden non-muslim bank konvensional tidak mengetahui bagaimana kondisi pelayanan di bank syariah, sehingga mereka tidak mampu menjawab pertanyaan mengenai variabel pelayanan dengan tepat.

Variabel promosi memiliki parameter positif dengan odd ratio sebesar 1.261, tetapi variabel ini juga tidak berpengaruh nyata terhadap keputusan nasabah non-muslim dalam menggunakan jasa bank syariah. Hal ini dapat disebabkan karena masyarakat non-muslim cenderung menghiraukan promosi mengenai bank syariah, baik di tempat umum ataupun di media. Mereka akan lebih percaya jika mendapatkan informasi mulut ke mulut dari teman yang mereka kenal atau penjelasan dari marketing bank untuk masalah pembiayaan usaha.

Variabel produk memiliki parameter positif dengan odd ratio 1.268, tetapi tidak berpengaruh nyata. Hal ini dapat dikarenakan nasabah non-muslim bank konvensional juga banyak yang belum memahami dan mengerti mengenai macam-macam produk bank syariah dengan baik.

\section{SIMPULAN DAN SARAN}

\section{Simpulan}

Hasil pemaparan pengolahan dan analisis data diatas, dapat disimpulkan bahwa :

1. Kecenderungan nasabah non-muslim terhadap bank syariah di Jakarta mendapatkan informasi terbanyak dari teman/orang lain dan internet masingmasing sebesar $23.7 \%$, sebanyak $68 \%$ dari responden non-muslim bank syariah menganggap bank syariah lebih unggul dibandingkan bank konvensional, alasan terbesar yang menganggap bank syariah lebih unggul, karena produk bank syariah lebih transparan sebesar $46.34 \%$. 96\% nasabah non-muslim bank syariah juga merupakan nasabah bank konvensional, alasan terbesar responden non-muslim bank syariah menjadi nasabah di bank konvensional adalah 30\% menganggap lokasi kantor cabang dan ATM bank konvensional mudah ditemukan.

2. Keputusan menggunakan jasa bank syariah pada nasabah non-muslim di Jakarta dipengaruhi oleh variabel lokasi dengan nilai odd ratio sebesar 1.450 , variabel keuntungan administratif dengan nilai odd ratio sebesar 6.790, dan variabel stimulan religi dengan nilai odd ratio sebesar 2.679. 


\section{Saran}

Berdasarkan hasil penelitian faktor-faktor yang memengaruhi nasabah non-muslim dalam menggunakan jasa bank syariah adalah lokasi, keuntungan administratif, dan stimulan religi, maka beberapa saran yang dapat diajukan adalah

1. Bank syariah masih harus meningkatkan jumlah kantor cabang dan ATM yang mudah ditemui masyarakat baik disekitar kawasan industri atau pabrik, perkantoran, pasar, maupun perumahan. Ekspansi kantor cabang dan ATM bank syariah jangan hanya terpusat di pulau Jawa, tetapi juga di luar pulau Jawa agar pasar domestik perbankan syariah dapat kita kelola terlebih dahulu sebelum masuknya pasar asing. Nasabah non-muslim yang masih tergolong dalam nasabah floating mass sering kali tidak menyadari keberadaan lokasi bank syariah. Beberapa kantor cabang bank syariah masih berada di daerah pertokoan yang tidak banyak dilalui masyarakat, dan tidak terlihat mencolok. Bank syariah harus memikirkan letak strategis kantor cabang yang dapat dengan mudah dilihat dan mencolok perhatian masyarakat.

2. Pembebasan biaya ATM dan transakasi lain dapat juga diaplikasikan oleh beberapa bank syariah lain sebagai upaya menarik nasabah non-muslim. Pada beberapa etnis tertentu, mereka sangat teliti dalam perhitungan biaya dan bonus yang akan didapatkan. Bank syariah juga telah memberikan bonus dan hadiah kepada nasabahnya. Pemilihan jenis bonus yang diberikan ataupun hadiah barang yang diberikan harus diperhatikan dengan teliti hingga detail terkecil agar memberikan kepuasan yang maksimal kepada nasabah. Hubungan kerjasama dengan merchant atau dengan bank lain sehingga pengguna jasa bank syariah dapat menikmati potongan harga juga dapat dilakukan sebagai salah satu upaya menarik nasabah non-muslim.

3. Kepercayaan lain juga melarang untuk mengambil riba, prinsip bank syariah yang tanpa riba sebenarnya dapat diterima oleh pemeluk agama lain. Agar mampu menarik nasabah non-muslim, bank syariah dapat membuat bentuk promosi yang lebih universal dengan istilah yang dapat dipahami pemeluk agama lain.

\section{DAFTAR PUSTAKA}

Alamsyah H. 2012. Perkembangan dan Prospek Perbankan SyariahIndonesia:

Tantangan Dalam Menyongsong MEA 2015. [internet]. [diunduh : 2014 Februari 14]. Tersedia pada : http://www.bi.go.id 
Alquran Tajwid dan Terjemahannya. Bandung (ID) : PT Syaamil Cipta Media

Amirudin. 2010. Studi Pereferensi dan Segmentasi Pasar BRI Syariah

(Kasus Masyarakat Kota Bogor). [Skripsi]. Bogor (ID) : Institut Pertanian Bogor

[BI] Bank Indonesia. 2013. Statistik Perbankan Syariah.[internet]. [diunduh 2014 Mei 29]. Tersedia pada: http//www.bi.go.id

BNI Syariah. 2011. [internet]. [diunduh 2014 Juli 18]. Tersedia pada : http://www.bnisyariah.co.id

[BPS] Badan Pusat Statistisk. 2013. Publikasi. [internet]. [diunduh 2014 mei 29]. Tersedia pada : http://www.bps.go.id

BRISyariah.2011. [internet]. [diunduh 2014 Juli 18]. Tersedia pada : http://www.brisyariah.co.id

Bank Syariah Mandiri. 2012. [internet]. [diunduh 2014 Juli 18]. Tersedia pada : http://www.syariahmandiri.co.id

Gujarati D, Zain S. 1999. Ekonometrika Dasar. Jakarta (ID): Erlangga

Haron S, Ahmad N, dan Planisek S. 1994. Bank Patronage Factors of Muslim and NonMuslim Customers. Malaysia

Hasan SA, Subhani MI, Osman A. 2012. Consumer Criteria for the Selection of anIslamic Bank: Evidence from Pakistan. MPRA Paper No. 40384, Juli 2012.

Humaeamah R.2006. Faktor-faktor yang Memengaruhi Etnis Cina Non-Muslim menjadi Nasabah di Bank Syariah (Studi Kasus : PT Bank Mega Syariah Indonesia). [Skripsi]. Depok (ID) : Universitas Indonesia

[IFSB] Islamic Financial Services Board. 2014. Islamic Financial Services Industry Stability Report 2014. [internet]. [diunduh 2014 Juli 9]. Tersedia pada : http://www.ifsb.org

Kamus Besar Bahasa Indonesia. 2012. [online]. Tersedia pada : http://www.kbbi.web.id

Kasmir. 2005. Pemasaran Bank. Jakarta (ID) : Kencana

[KEMENAG] Kementrian Agama. 2012. Laporan Tahunan Kehidupan Keagamaan di Indonesia 2012. [internet]. [diunduh 2014 Juli 10]. Tersedia pada : http://www.kemenag.go.id

Machmudah R. 2009. Faktor-faktor yang Mempengaruhi Minat Nasabah Non-Muslim Menjadi Nasabah di Bank Syariah (Studi Pada Bank CIMB Niaga Syariah Cabang Semarang).[Skripsi]. Semarang (ID): Institut Agama Islam Negri Walisongo Semarang

Mutasowifin A. 2003. Menggagas Strategi Pengembangan Perbankan Syariah di Pasar NonMuslim. Jurnal Universitas ParamadinaVolume 11, No.1, September 2003

Nachrowi DN. 2002. Penggunaan Teknik Ekonometri. Jakarta (ID) : PT RajaGrafindo Persada

Nawawi I. 2008. Ekonomi Islam Perspektif Teori, Sistem, dan Aspek Hukum. Surabaya (ID): Putra Media Nusantara

Nurul H, Handi R, Mustafa E, dan Ranti W. 2008. Ekonomi Makro Islam Pendekatan Teoritis. Jakarta (ID) : Kencana

Rahayu S. 2005. SPSS Versi 12.00 dalam Riset Pemasaran. Bandung (ID) : Alfabeta

Setiasih D. 2011. Analisis Persepsi, Preferensi, Sikap dan Perilaku Dosen Terhadap Perbankan Syariah (Studi Kasus pada Dosen Fakultas Syariah IAIN Walisongo Semarang ). [Skripsi]. Semarang (ID): Institut Agama Islam Negri Walisongo Semarang

Sugiyono PD. 2008. Metode Penelitian Kuantitatif dan Kualitatif dan R\&D. Bandung (ID): Alfabeta

Supranto J. 2004. Ekonometri. Jakarta (ID): Ghalia Indonesia

Suliyanto. 2005. Analisis Data dalam Aplikasi Pemasaran. Bogor (ID): Ghalia Indonesia

Zamir I, Abbas M. 2008. Pengantar Keuangan Islam Teori \& Praktik. Jakarta (ID) : Kencana 
Ziliwu, V. 2008. Analisis Faktor-faktor yang Mempengaruhi Nasabah dalam Menggunakan Tabungan Syariah Plus pada Bank BNI Syariah di Jakarta. [Skripsi]. Bogor (ID): Institut Pertanian Bogor 